\title{
Entrevista com Johannes Angermuller
}

\author{
Luciana Salazar Salgado* \\ Letícia Clares** \\ Tradução: Gustavo Primo***
}

Johannes Angermuller tem formação em Sociologia e Linguística, com doutorado em Análise do Discurso por um programa de cotutela das universidades Paris 12, na França, e de Magdeburg, na Alemanha. É professor de Discurso, Linguagens e Linguística Aplicada vinculado à Open University, em Milton Keynes (UK), ao Centre for Applied Linguistics de Warwick, em Coventry (UK), e ao Centre d'étude des mouvements sociaux da École des hautes études en sciences sociales, em Paris (France). Também é presidente fundador da DiscurseNet - International Association for Discourse Studies, uma rede interinstitucional de pesquisadores discursistas. Conhecido por suas pesquisas sobre os discursos científico e político, sobretudo o pós-estruturalismo, atualmente está interessado nos Estudos de Ciência e Tecnologia e no trabalho qualitativo e teórico em torno das construções discursivas das posições de sujeito e da pragmática enunciativa.

* PPGL, PPGLit-UFSCar/IEB-USP, doutora em Linguística, docente pesquisadora. Membro do Grupo de Pesquisa CNPq Comunica - inscrições linguísticas na comunicação, integrante do Laboratório de Escritas Profissionais e Processos de Edição - Labeppe (UFSCar-SP/CEFET-MG). https://orcid.org/0000-0002-1052-0726.

* PPGL-UFSCar, mestra e doutoranda em Linguística. Membros do Grupo de Pesquisa CNPq Comunica - inscrições linguísticas na comunicação, integrante do Laboratório de Escritas Profissionais e Processos de Edição - Labeppe (UFSCar-SP/CEFETMG). https://orcid.org/0000-0001-7501-1984.

* Unesp, mestre em Estudos de Literatura (PPGLit-UFSCar), professor de inglês para propósitos acadêmicos, bolsista de treinamento técnico no programa Brazilian Virtual Exchange. Membros do Grupo de Pesquisa CNPq Comunica - inscrições linguísticas na comunicação, integrante do Laboratório de Escritas Profissionais e Processos de Edição - Labeppe (UFSCar-SP/ CEFET-MG). https://orcid.org/0000-0002-8431-9144. 
Salgado e Clares: Em seu trabalho Discours académique et gouvernementalité entrepreneuriale. Des textes aux chiffres, publicado em 2013, ${ }^{1}$ recorrendo a Laclau (1990), ${ }^{2}$ Latour $(2001)^{3}$ e Luhmann (1998), ${ }^{4}$ você afirma que "A la societé s'est substitué le terrain ouvert, instable et hererogène du social, dans lequel nous devons en quelque sorte naviguer, en depit des inegalités de terrain, des chausse-trappes et des points aveugles [...]” (p. 81).

Gostaríamos que retomasse essa afirmação levando em conta o contexto da pandemia global já em seu segundo ano, 2021, em que se intensificaram as trocas comunicacionais e a distribuição de informação, sobretudo digitalmente. Temos discutido a hiperdigitalização nestes termos: "A distribuição dos dizeres hoje hegemônica se dá nos dispositivos digitais, nos quais uma tela tem efeito de ponto de partida dos sentidos, mas, de fato, a própria projeção de um texto numa tela decorre de operações bastante sofisticadas, em que pacotes de informação trafegam por infovias e combinam-se conforme uma programação engenhada antes de sua configuração textual, alhures." (SALGADO, 2021). ${ }^{5}$ Dessa perspectiva, podemos dizer que as armadilhas e os pontos cegos terão mudado na atual conjuntura?

Angermuller: Escrevi aquele artigo dez anos atrás, tendo em mente que há um conflito contínuo entre práticas de unificação e diversificação no espaço social global. Deleuze e Guattari

1 ANGERMULLER, Johannes. Discours académique et gouvernementalité entrepreneuriale. Des textes aux chiffres. In: LEBARON, Frédéric; ANGERMULLER, Johannes; TEMMAR, Malika (ed.). Les discours sur l'économie. Paris: Presses Universitaires du Septentrion, 2013. p. 71-84.

2 LACLAU, Ernesto. New Reflections on the Revolution of Our Time. London: Verso, 1990.

3 LATOUR, Bruno. A esperança de Pandora: ensaios sobre a realidade dos estudos científicos. São Paulo: EDUSC, 2001.

4 LUHMANN, Niklas. Organización y decisión. Autopiesis, acción y entendimiento comunicativo. Barcelona: Anthropos; Universidad Iberoamericana, 1998.

5 SALGADO, Luciana Salazar. A dimensão algorítmica do rumor público e o viver na pandemia. In: MOTA, André (org.). Sobre a pandemia: experiências, tempos \& reflexões. São Paulo: Hucitec, 2021. p. 77-99. 
(1988), em A Thousand Plateaus, ${ }^{6}$ falam sobre territorialização e desterritorialização. O caso da Academia ilustra bem essas ideias. Com seus vários campos hiperespecializados, o espaço acadêmico é extremamente heterogêneo, ao mesmo tempo que ranqueamentos, índices de qualidade e outros métodos de compatibilidade de métricas trazem uma certa homogeneidade métrica entre áreas de conhecimento e países. Essa tendência pode ser problemática ao se pensar no efeito sufocante dos números na criatividade científica.

A Academia é meu exemplo para teorizar a relação entre práticas de desterritorialização do social versus as estruturas territorializadas da sociedade global de hoje. Assim mesmo, nos últimos dez anos, as forças de territorialização global se tornaram ainda mais dominantes, especialmente por conta do triunfo das tecnologias sociais. Essas tecnologias agora permeiam o espaço social global de maneiras muito diversas e cotidianas. Como consequência disso, o social está perdendo sua opacidade e rugosidade, e certos nichos até então protegidos se tornaram objeto de mecanismos de controle. O amor agora tem que passar pelo Tinder, aplicativo que revolucionou o modo como as pessoas se relacionam, enquanto a conta de Twitter de Donald Trump dominou a esfera política por vários anos. Isso tem a ver com um rearranjo fundamental de forças globais de poder que impacta muito mais profundamente na vida cotidiana e tem um alcance global maior do que nunca.

Um aspecto dessa transformação é a criação de pouquíssimas posições de sujeito no espaço digital que são hipervisíveis e capturam toda a atenção das massas, que, por sua vez, são enormes, mas não têm voz. Essa concentração de visibilidade

6 DELeUZE, Gilles; GUATTARI, Félix. A Thousand Plateaus. Capitalism and Schizophrenia. London: The Athlone Press, 1988. 
pode ser observada na Academia (ANGERMULLER; HAMANN, 2019), ${ }^{7}$ mas também na sociedade em geral, dada a fascinação que se tem pela celebridade (ANGERMULLER, 2018). ${ }^{8}$

Salgado e Clares: Essa questão da comunicação hiperdigital se inscreve numa discussão mais ampla sobre o que se tem chamado globalmente de fake news, um fenômeno que não é novo, mas decerto está renovado por novas formas de difusão. Em seu livro ¿Quién dijo posestructuralismo? La creación de una generación intelectual, publicado na Espanha em 2019, você escreve que "Leer textos en nuevos contextos no hace que su interpretación sea menos verdadera". Gostaríamos que você tratasse dessa afirmação considerando a atual conjuntura mundial, em que textos com informações falsas são muito frequentemente lidos como verdadeiros, o que parece estar ligado ao funcionamento de práticas fortemente automatizadas, incorporadas nas redes de troca em praticamente todas as organizações sociais do atual período, que o geógrafo Milton Santos $(1996 ; 2000)^{9}$ designou como período técnico-científico informacional. Em mensageiros como o WhatsApp, por exemplo, a dêixis discursiva sofre transformações importantes, recolocando a questão do fiador do discurso, entre outras. Em redes como TikTok, o borramento entre fabulação e documentação do real chega ao paroxismo. Que se passa com as balizas necessárias à produção dos sentidos, que sustentam a atividade de interpretação dos conteúdos postos em

\footnotetext{
7 ANGERMULLER, Johannes; HAMANN, Julian. The Celebrity Logics of the Academic Field. The Unequal Distribution of Citation Visibility of Applied Linguistics Professors in Germany, France, and the United Kingdom. Journal for Discourse Studies, n. 1, 2019.

8 ANGERMULLER, Johannes. Accumulating Discursive Capital, Valuating Subject Positions. From Marx to Foucault. Critical Discourse Studies, v. 15, p. 414-425, 2018.

9 SANTOS, Milton. A natureza do espaço. Técnica e tempo. Razão e emoção. 1. ed. São Paulo: Hucitec, 1996; SANTOS, Milton. Por uma outra globalização. 1. ed. São Paulo: Record, 2000.
} 
circulação?

Angermuller: Estamos vivendo uma nova revolução nas tecnologias midiáticas e de comunicação. Grandes agitações sociais e políticas puderam ser observadas depois que a imprensa foi inventada (o que levou a 150 anos de conflitos religiosos na Europa) e quando as ondas de rádio começaram a ser transmitidas e captadas (será que Hitler e a Segunda Guerra Mundial teriam acontecido sem essa tecnologia?). Mas a grande novidade de hoje são as mídias sociais. Elas estabeleceram um regime de visibilidade extremamente desigual entre aqueles que monopolizam a atenção de todos os outros usuários. Os dispositivos que dão suporte às mídias sociais também agem em nosso cérebro e nossos sentidos de maneiras que aumentaram a intensidade afetiva com que notícias e mensagens circulam em nossos telefones e computadores. Trump [eleito presidente dos EUA em 2016] e Bolsonaro [eleito presidente do Brasil em 2018] são certamente sintomas ideológicos dessa virada sociotecnológica. De fato, as tecnologias de mídias sociais parecem nos fornecer material ideológico muito mais diretamente do que o rádio ou a TV já conseguiram. Deveríamos, então, ser críticos ao pensar na vida pública em termos de uma deliberação racional do que sejam os interesses de todos ou o bem comum e levar a sério também nas dimensões irracionais, emocionais e afetivas dos discursos que agora estão conectados com nosso aparato biomaterial de percepção - por exemplo, nossos olhos colados na tela de um smartphone. Acredito que essa grande visibilidade dada a poucas - e, às vezes, inconsequentes figuras que querem chamar a atenção, assim como os efeitos de amplificação de afetos causados pela comunicação tela a tela, 
levaram à deterioração do debate público e à ascensão de uma política psicótica de direita.

Salgado e Clares: Essa difusão das informações produzindo intenso rumor público nos remete às reflexões sobre o trabalho intelectual e, portanto, ao ambiente acadêmico e aos diversos entendimentos do que seja a ciência, sua função social etc. No atual contexto de emergência sanitária mundial, parece evidente ao grande público que áreas da saúde e algumas engenharias se envolvam com as questões urgentes que se impõem (procedimentos clínicos e logísticos, desenvolvimento de vacinas e respiradores etc.), mas as questões comunicacionais, igualmente cruciais, em geral não são vistas como constitutivas do modo como conduzimos o combate à pandemia. Diante desse quadro, quais são, a seu ver, as contribuições possíveis do campo em que se inscrevem pesquisas em Linguística, Linguística Aplicada e Análise do Discurso?.

Angermuller: Bom, minha impressão é de que nós, analistas do discurso, não precisamos nos justificar desde que aconteceram coisas como Trump, Bolsonaro, ou o Brexit [Britain Exit, a saída do Reino Unido da União Europeia, processo que se iniciou em 2017 e se concluiu em 2020]. Agora todo mundo compreende o poder da comunicação e das dinâmicas discursivas em grandes comunidades. Figuras muito medíocres mantêm o público ocupado ao criarem "tempestades de indignação" e controvérsias envolvendo mentiras estratégicas. É importante investigar os mecanismos desses processos e também aprender como resistir a eles. A linguagem é, claro, a chave de tudo, mas também precisamos ter uma abordagem interdisciplinar se quisermos 
dar conta das muitas facetas das fake news que proliferam no espaço digital global. Devemos fazer mais pesquisa sociológica sobre as práticas e estruturas em que as fake news emergem. Temos também que prestar atenção em acontecimentos similares do passado (penso na Alemanha nazista). Há, agora, novos recursos semióticos e dispositivos linguísticos mobilizados na comunicação on-line. Devemos ainda estudar suas dimensões cognitivas e psicológicas.

Salgado e Clares: No que tange à ciência, aos cientistas e aos parâmetros que eles propõem para as decisões políticas, o atual contexto pandêmico tem mostrado que são diversos os desafios: há negacionismos de toda sorte e também disputas relativas a protocolos adequados, a produtos científicos legítimos, relações com o meio ambiente e a sociedade etc. Como você avalia o papel da comunicação científica na construção desse lugar do que é referido por ciência hoje?

No Brasil, temos discutido o que se pode designar como "quatro questões fundamentais regedoras da comunicação científica hoje: 1. a dominação das ciências exatas e naturais com relação às ciências humanas; 2 . as pressões de avaliação quantitativa de periódicos e de pesquisadores; 3 . as pressões pela internacionalização das publicações científicas; 4. a mudança tecnológica dada pelo uso de plataformas. Considerando que o entrelaçamento delas engendra um regime de funcionamento da comunicação científica atual, definindo-a como produção de uma 'comunidade científica', chegamos a um problema de fundo que nos leva à seguinte hipótese de trabalho: em termos discursivos, trata-se de uma instituição discursiva cuja sustentação é dada pelo convívio de diferentes comunidades discursivas, definidas 
por áreas, talvez, ou por campos, ou disciplinas... Categorias de difícil definição, pois se trata de considerar a escala do vivido, na qual as pesquisas e as escritas efetivamente se dão."(SALGADO; CLARES, 2017).${ }^{10}$ Esses aspectos constitutivos da comunicação científica podem ser complicadores na sua divulgação para leigos, que frequentemente é bastante estereotípica. Seria possível dizer que as injunções e os apagamentos que têm organizado a comunicação científica interferem na sua difusão para públicos mais amplos?

Angermuller: Certamente, a reputação dos cientistas é crucial no modo como são vistos pelo público. Sua reputação como figuras públicas é um dos muitos aspectos considerados por quem recebe a mensagem, quando esta circula num espaço social heterogêneo. Quando os pronunciamentos dos cientistas entram na esfera política, eles são geralmente enquadrados em antagonismos políticos, como esquerda versus direita, o que não faz necessariamente muito sentido, se pensarmos no mundo da ciência. Então, coisas surpreendentes podem acontecer com cientistas mais desavisados quando afirmam certos fatos, mesmo que alguns campos científicos já estejam fortemente conectados com o debate político (por exemplo, a climatologia). Às vezes, não é coincidência que certas alegações científicas ganhem adesão na arena política. Os enunciadores de tais alegações geralmente têm interesse e experiência na área de criação de políticas públicas e sabem como vender suas ideias. Mas é claro também que a vasta maioria dos cientistas não encontra adesão nenhuma fora de suas áreas de concentração e, na minha

10 SALGADO, Luciana Salazar; CLARES, Letícia Moreira. Mediação editorial em artigos científicos: um estudo de injunções e apagamentos nas humanidades. Revista do GEL, São Paulo, v. 14, n. 3, p. 29-58, 2017. Disponível em: https://revistas.gel.org. br/rg/article/view/1886. Acesso em: 4 nov. 2021. 
opinião, a questão tem a ver com identificar 1) por que somente pouquíssimos cientistas enxergam certas demandas e recebem uma devolutiva e 2) o que é que se considera como "a ciência" nos discursos públicos, já que normalmente os cientistas nunca chegam a um consenso em nada.

Não estou dizendo que todas as afirmações científicas são iguais. Certamente, há algumas que são mais verdadeiras que outras! Mesmo assim, devemos reconhecer que algo muito significativo acontece quando afirmações que saem de debates científicos entram em debates mais públicos e são recontextualizadas de várias e decisivas maneiras. O que observamos hoje, por exemplo, é que pessoas de esquerda ou do centro são mais propícias a confiar na "ciência" e reivindicar sua autoridade (pensemos nos índices de vacinação sendo bem maiores entre os Democratas nos Estados Unidos), enquanto os Trumpistas (e seus equivalentes ao redor do mundo) apresentam uma postura hipercrítica que os leva a rejeitar qualquer afirmação científica que não se alinhe às suas visões de mundo (não nos esqueçamos de que esse comportamento também se observa na esquerda, se pensarmos nas controvérsias em torno da engenharia genética ou a energia nuclear). Portanto, quando Democratas e Republicanos se referem aos "conhecimentos científicos" em debates públicos, um aspecto importante a se observar é como essa dita "ciência" se inscreve nas diferentes identidades políticas. Curiosamente, identidades de direita parecem ser cada vez mais incompatíveis com o que é considerado "ciência" por liberais ou pessoas de esquerda.

Salgado e Clares: Poderia nos contar um pouco do atual estágio de suas pesquisas? 
Angermuller: Tenho me interessado pela questão da verdade no discurso (ANGERMULLER, 2018) ${ }^{11}$ e feito uma incursão pelos Estudos de Ciência e Tecnologia. Muitos linguistas estão interessados nos aspectos políticos e sociais da língua, mas geralmente não vão além de citar algumas referências da Análise Crítica do Discurso, que tende a moralizar questões sociais em vez de estudá-las. Já os Estudos de Ciência e Tecnologia têm sido uma área extremamente produtiva, inclusive teoricamente, com seus esforços para unir tradições construtivistas e materialistas. Têm acontecido boas conversas num grupo pequeno de linguistas interacionistas desde os anos 1980, mas os linguistas mainstream e analistas de discurso têm dado apenas, quando muito, uma olhada superficial nesses debates. Penso que devemos nos engajar em debates teóricos sobre essas questões e ser mais críticos sobre certas afirmações que queremos fazer sobre linguística e as realidades sociais. Precisamos fazer mais pesquisa sistemática em vez de confiar em nossa intuição, que muitas vezes aponta para caminhos errados. Por isso, tenho me interessado em dar atenção ao comportamento social e discursivo real de grandes populações acadêmicas, o que tem me levado a testar instrumentos quantitativos de pesquisa social. Também persisto com meu trabalho mais qualitativo e teórico sobre a construção das posições dos sujeitos e a pragmática enunciativa.

Recebido em: 15/08/2021//Aceito em 11/09/2021.

11 ANGERMULLER, Johannes. Truth after Post-Truth: For a Strong Programme in Discourse Studies. Palgrave Communications, 2018. 